\title{
Ventilated Chamber System for Continuous Recording of Both the Evaporation Rate and the Heart Balance at the Bare Soil Surface
}

\author{
Ali Albed-Rahman MOHAMED*, Kunio WATANABE** and Tai SASAKI***
}

\section{裸地表面におけるベンチレーション法による蒸発量と熱の連続測定}

\author{
アリ・モハメド*・渡辺邦夫**・佐々木泰***
}

\begin{abstract}
This paper describes the design of a new ventilated chamber system for continuous measurement of both the evaporation rate and the energy balance components at the bare soil surface with some of its principle advantages and characteristics. The influence of the used equipment on both of the temperature of the air and its relative humidity was studied and minimized. The air velocity inside the chamber has been regulated to be a logarithmic function of the height above the soil surface. The change of static pressure within the chamber compared with the ambient pressure was modeled well as a linear function of the volumetric flow rate of the air. A new method was proposed to estimate the diurnal variation of the net radiation, latent heat, sensible heat and soil heat fluxes at the bare soil surface. Twenty four hours in-situ measurement was carried out at Rokkasho Low-level Radioactive Waste Disposal Center, Aomori Prefecture, Japan, to check the operational effectiveness of the new device and the reliability of the proposed method for experimental periods of many days. Also, an accurate estimation of the evaporation rate from the soil surface for such type of places is indispensable, for evaluating safety concerning radioactive wastes. The value of the evaporation rate from the ground surface is necessary for the simulation of the ground water flow near the surface. The downward net radiation flux, the air temperature, the air relative humidity, the air velocity and the soil temperature just beneath its surface were measured continuously through the day of the field
\end{abstract}

* Doctoral Student, Graduate School of Science and Engineering, Saitama University, Japan.

** Professor, Faculty of Engineering, Saitama University, Japan.

*** Civil and Architectural Engineering Department, Japan Nuclear Fuel Limited, Tokyo, Japan. 
experiment. The evaporation rate, the latent heat flux, the sensible heat flux and the soil heat flux were calculated from the measured data. To check the accuracy of this new method, the soil heat flux was measured directly with two soil heat flux meters through a part time of the field experiment. A comparison between the measured values and those have been resulted from this method was made. Also, the transient change of the total percentage of error was calculated through the period of the soil heat flux measurement. The obtained results give a strong indicator that this method is suitable for estimating the energy balance components at the bare soil surface. This new method has the advantage of that it needs only simple data and it wears an aspect of certainty.

Key Words: soil evaporation, net radiation, latent heat, sensible heat, soil heat flux.

\section{要 旨}

土壤表面からの正確な蒸発量の測定は地下水流動解析では重要である。裸地表面におけ る蒸発量と熱収支を連続測定するために作成したベンチレーション法装置についての有効 性と特徵について検討した。使用した装置が空気の温度と相対湿度へ与える影響が小さく なるようにした。装置内部の風速分布は土の表面からの距離に対して対数法則に従うよう にした。装置内外の圧力の変化は装置を通過する空気の流量に対し線形関係でモデル化で きた。土の表面における正味放射、潜熱、顕熱、土中の熱流量の評価を実施した。原位置 における24時間測定を実施した。正味放射、気温、相対湿度、空気の流量、土の温度を測 定し、蒸発量、潜熱、顕熱、土中の熱流量を計算により求めた。測定方法の検証のために 土中の熱流量を熱流量計で直接測定し、計算值との差の時間変化を検討した。その結果、 裸地のエネルギー収支の評価方法としてこの方法が適切であることが分かった。この方法 は簡単なデー夕を得るだけで正確な測定ができるという点で有利である。

キーワード：土からの蒸発、正味放射、潜熱、顕熱、土中の熱流量

\section{Introduction}

The evaporation has a controlling influence on all hydrological processes and on many meteorological ones. Unfortunately, reliable estimates of the evaporation rate are extremely difficult to obtain. The water which evaporates at a bare soil surface is transported to the surface through the underlying layers of the soil profile. The exact formulation of this transport is rather complicated (e.g., Philip, 1957; De Vries, 1958;
Brutsaert, 1982), since the water transport takes place both in the liquid and vapor phase, involving not only pressure gradients and gravity but often also temperature gradients with a soil heat flux, and salt concentration gradients. Models of the evaporation from both bare soil and vegetated surfaces may be formulated as proportional to the difference in vapor pressure between the evaporating surface and the atmosphere, divided by the sum of the resistance parameters to the movement of the water vapor. These resistance 
parameters are generally specified as the surface resistance and the aerodynamic resistance. The surface resistance is intended to account for the obstructions to flow from the vapor source to a point just outside the surface, while the aerodynamic resistance is intended to account the resistance for vapor and sensible heat transport from the surface upward to some reference level.

Nowadays, the most common method for direct measurements of soil evaporation is the lysimetric method. Since the lysimetric method is time-consuming and labor intensive, the temporal resolution of the measurements is often limited to one day. Daily data of soil evaporation does not provide adequate information to study soil-atmosphere interactions. Recently, efforts have been made to use Time Domain Reflectometry (TDR) techniques to estimate soil evaporation by measuring changes in the soil water content (Plauborg, 1995; Iritz et al., 1997) or alternatively by a combination of the TDR technique and microlysimetry (Baker \& Spaans, 1994; Iritz et al., 1997).

Chambers have been used for several decades to measure fluxes of water and carbon dioxide from parts of plants, whole plants as well as from bare soil surfaces. It is well known that errors in the water flux measurements of such chambers are mainly caused by the alteration of the climate, e.g., temperature, humidity, radiation and the turbulence conditions within the chambers (e.g., Denmead, 1984; Leuning \& Foster, 1990; Iritz, 1997). In some chamber disigns, these problems have been solved by modifying and controlling the climate and by stirring the air within the chambers to reduce inadvertent effects of excessively large boundary layer resistance. These solutions are, however, costly and there still remain problems with the unnatural environmental conditions that are created within such chambers. With our design, our objectives are to minimize the chamber's influence on the natural conditions in the field and also to make a relatively cheap system to measure the evaporation rate precisely.

Determination of the diurnal variation of the net radiation, latent heat, sensible heat and soil heat fluxes requires the availability of some form of the energy distribution at a scale. This question can be treated quantitatively by considering the equation for the energy budget for a layer of surface material. Depending on the nature of the surface, this layer may consist of water, or of some other substrate like soil, canopy or snow; although this layer can be taken to be infinitesimally thin, it may sometimes even comprise a lake or a vegetational canopy over its entire depth. The order of magnitude and diurnal variation of the main terms in the energy budget equation have been investigated in the case of a grass covered surface (Pruitt et al., 1968; Brutsaert, 1982), in the case of mature and maize canopy (Perrier et al., 1976), at the surface of a deep water body (Yasuda, 1975), and at the surface of a shallow lake of a mean depth $2 \mathrm{~m}$ (Raupach, 1978). However, these methods require a very detailed models in order to describe the continuity of the heat fluxes at the interface proper1y. The authors of this paper present a fundamental study on a practical technique, which enables precisely to evaluate continuously the rate of the heat fluxes at the earth-atmosphere interface.

\section{Measuring apparatus}

The measuring apparatus mainly consists of five units: a chamber, a new equipment for measuring the evaporation rate has been designed by Watanabe \& Tsutsui (1994), a radiometer, a recorder and soil heat flux meters, as shown in Fig. 1.

The chamber has the shape of a rectangular 'box' lying on the soil surface and is made of Prespex for high transparency. The dimensions of the chamber are $0.80 \mathrm{~m}$ height, $0.50 \mathrm{~m}$ width and $1.20 \mathrm{~m}$ length, which covers a ground area of 
$0.60 \mathrm{~m}^{2}$. The chamber is divided into three compartments in the longitudinal direction: the inlet compartment, the central compartment and the outlet compartment (see Fig. 1). The inlet and outlet compartments constitute a distance of 20 $\mathrm{cm}$ of the length of the chamber, while the central compartment has a clear length of $98.8 \mathrm{~cm}$ as shown in Fig. 2. The three compartments are separated by two perforated transparent plates, each has a thickness of $0.60 \mathrm{~cm}$. Both of the two plates have 152 holes with diameter of $0.60 \mathrm{~cm}$. The holes are arranged in 8 horizontal lines and 19 vertical columns. While the horizontal distances between the columns are equal $(2.50 \mathrm{~cm})$, the vertical distances between the rows are regulated to give a logarithmic air velocity distribution in the vertical direction inside the central compartment (see Fig. 2). Each of the two perforated plates has an excess sharp length of $2.0 \mathrm{~cm}$ more than the height of the chamber, at its foot. This sharp excess is embedded in the soil during the measurement and it is useful to prevent the air leakage between the different compartments at the lower end of the separating plates. Also, both of the two vertical sides and the upper edge of each perforated plate are sealed to the chamber sides to prevent any air leakage. The ceiling of the central compartment has six measuring openings to provide the facility of inserting sensors to measure some parameters, e.g., temperature, relative humidity, pressure and air velocity within the chamber at any level above the surface (see Fig. 1). The air enters into the inlet compartment and goes out from the outlet compartment through two perforated pipes (one for each compartment). Both of the perforated pipes have $15.0 \mathrm{~cm}$ internal diameter, $16.0 \mathrm{~cm}$ external diameter and 8.0 $\mathrm{cm}$ length. The cylindrical surface of each pipe has 120 holes of $0.70 \mathrm{~cm}$ diameter, distributed regularly over its surface area. To force the air to pass through the core of the central compartment, two hollow cylindrical pipes are used in the inlet and outlet compartments. Each cylinder has a length of $9.2 \mathrm{~cm}$, an internal diameter of $38.2 \mathrm{~cm}$ and an external diameter of $38.3 \mathrm{~cm}$. These two cylindrical pipes are placed in a position that their axes are in coincide with the axes of the two perforated pipes. The vertical sides of the chamber are strengthened by stiffening plates, each has a width of $10 \mathrm{~cm}$ and a thickness of $1.0 \mathrm{~cm}$. Also, there are two transparent solid pipes, each has a diameter of $3.0 \mathrm{~cm}$, used to increase the stiffness of the chamber in the lateral direction (see Fig. 2).

Although the dimensions are different, the same technique that was disigned by Watanabe \& Tsutsui (1994) has been used to measure the evaporation rate. The main idea of this technique depends on covering some parts of the ground surface with a box made of transparent sheet, injecting air from one side and extracting this air from the opposite side. The absolute humidity of the extracted air will be larger than that of the injected air when the vapor comes out from the ground surface by evaporation and/or evapotranspiration. The air can be passed through the chamber by either a blower system or a suction system. In this study, the later system has been used as shown in Fig. 1 to avoid some deficits of the first one as it will be explained later. To keep the temperature of the air during its movement between the different parts of the equipment, plastic hose pipes covered by an insulation material are used to carry the air. During the experiment both the the temperature and relative humidity of the air are measured just before and after passing through the chamber. Also, the volumetric flow rate of the air is measured continuously through the experiment. Kurokawa et al. (1995) have checked the accuracy of this equipment for measuring both of the evaporation and evapotranspiration rates.

A radiometer positioned at $0.30 \mathrm{~m}$ above the ground surface and located outside the chamber is used to measure the net radiation as shown in Fig. 1. The radiation components are measured in the short-wave and long-wave ranges. Two 
solarimeters, one for exposure from above and one for exposure from below, are used for measurements. Net radiation from the upper and lower hemispheres are recorded using a radiation balance meter.

Ten thermistors are used to measure the temperature of the soil just beneath its surface and connected directly to a recorder as shown in Fig. 1.

The soil heat flux is measured with two heat flux meters. The sensors were buried $1.0 \mathrm{~cm}$ under the soil surface (inside the central compartment), as shown in Figs. 1 and 2.

\section{On the control of the chamber system}

\subsection{Ventilation system}

The chamber can be ventilated by either a pushed or a sucked air system. To use the pushed air system in the ventilation process, the air has to be passed through a blower (electric pump) before entering into the chamber. Thus, the temperature of the air may be raised by the heat from the motor of the pump conducted by the axis to the propeller and the friction heat created as a

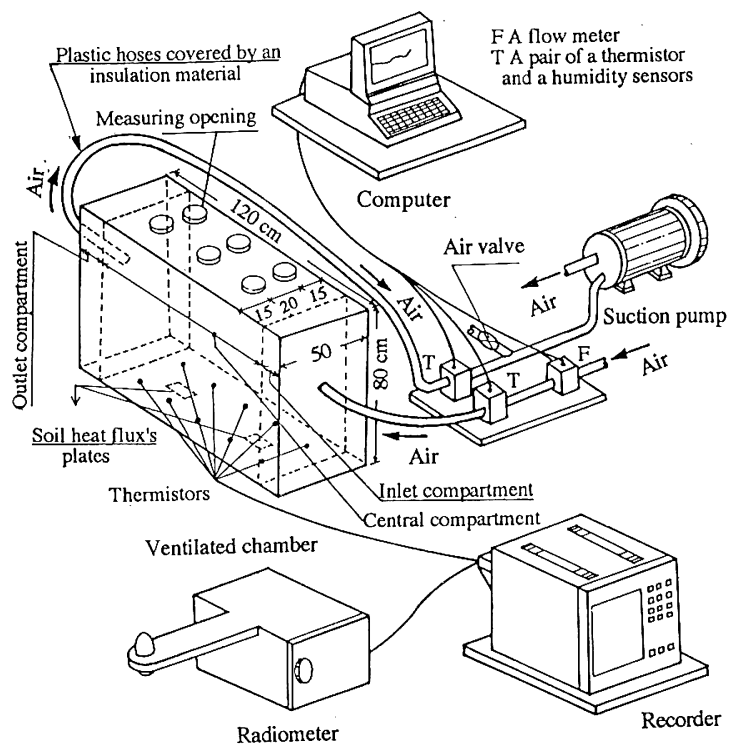

Fig. 1 Schematic view of the measuring equipment. result of the fast rotating propeller. To check this effect of the pump, a field experiment was done in the Campus of Saitama University, Japan, on March 24, 1997, from 6 A.M. to 8 P.M. A detailed description about the evaporation measuring equipment of that field experiment is not necessary here because this is just a check on the pumping effects. The temperature of the air was measured just before and after passing through the pump. The value of the relative humidity of the air during the time of that field experiment was varying between $92.4 \%$ as a maximum value observed at 6 A.M. and $40.0 \%$ as a minimum value observed at 3:30 P.M. The transient change of the temperature of the air just before and after passing through the pump during that field experiment is illustrated in Fig. 3. It was found that the maximum temperature of the air was changed from $10.2{ }^{\circ} \mathrm{C}$ to $14.4{ }^{\circ} \mathrm{C}$ at 2 P.M. while the minimum temperature of the air was changed from $3.0^{\circ} \mathrm{C}$ to $5.6^{\circ} \mathrm{C}$ at 8 P.M. The results of that field experiment show that the temperature of the air was raised by about $4{ }^{\circ} \mathrm{C}$ due to the conducted heat from the pump.

In fact, at a constant absolute humidity of the air, its relative humidity decreases when its temperature increases and vice versa. As an example; if the original temperature of the air mass is $15^{\circ} \mathrm{C}$ and its relative humidity is $60 \%$ (absolute humidity $=7.68 \mathrm{~g} / \mathrm{m}^{3}$ ), for the same absolute humidity, the relationship between its relative humidity and temperature in the range from

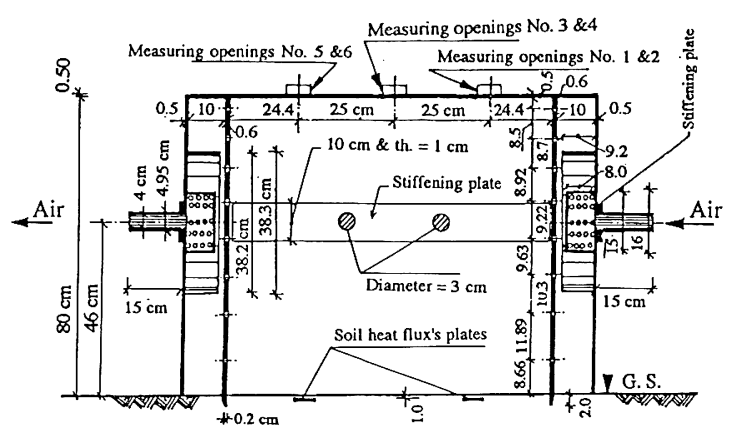

Fig. 2 Longitudinal section through the center line of the ventilation chamber. 
$10{ }^{\circ} \mathrm{C}$ to $20{ }^{\circ} \mathrm{C}$ is as shown in Fig. 4. From this figure, it is observed that at a constant absolute humidity of the air, its temperature has a great influence on its relative humidity.

To clarify the effect of the relative humidity of the air on the evaporation rate, a laboratory experiment was done on a fine sand (Toyoura standard sand) in a constant temperature room. The temperature of the air was $27.3{ }^{\circ} \mathrm{C}$ and its velocity was kept constant during the experiment. Also, the saturation ratio in the top layer of the sand was constant through the experiment by providing a constant water table at a depth of $32.0 \mathrm{~cm}$ from the surface. The laboratory experiment was carried out by another evaporation measuring equipment. Although both of the two

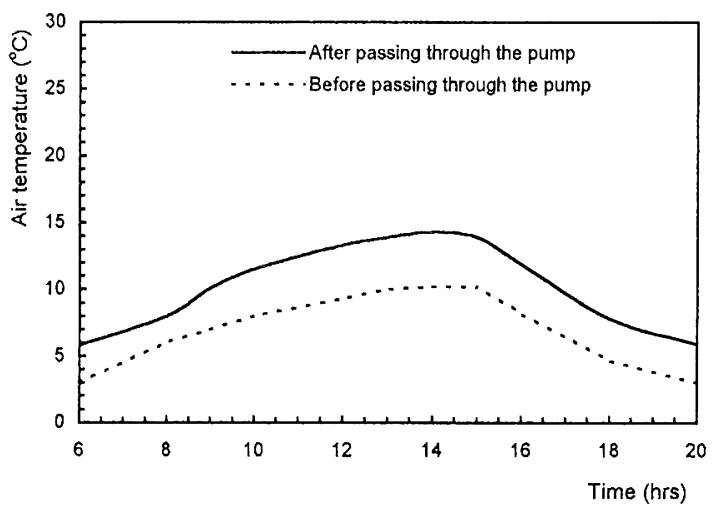

Fig. 3 Effect of the pump on the air temperature through a field experiment on March 24, 1997.

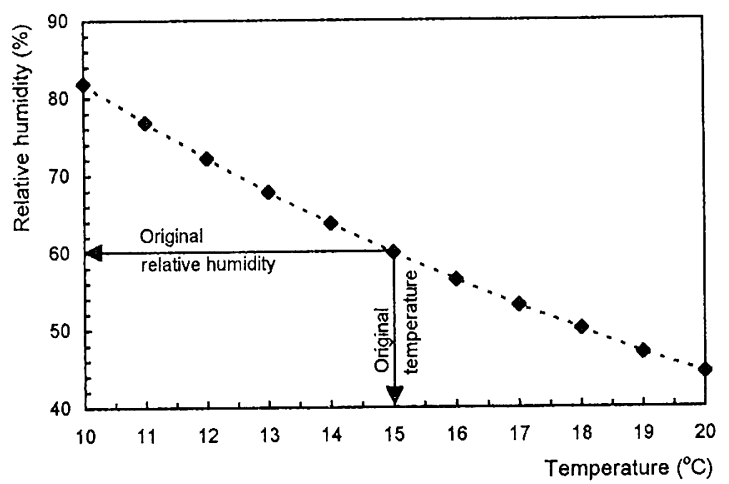

Fig. 4 Relationship between the temperature and the relative humidity of the air at a constant absolute humidity. equipment have the same technique to measure the evaporation rate but the dimensions, shape facilities of the ventilation box of that laboratory equipment are different from those of the ventilated chamber of the equipment shown in Fig. 1. Further details about that equipment has been explained by Mohamed et al. (1997). The effect of the relative humidity of the air on the evaporation rate during that laboratory experiment is illustrated in Fig. 5. It was observed that the value of the evaporation rate decreases as the relative humidity of the air increases while the temperature of the air, its velocity and the saturation ratio in the top layer of the sand were constants. Also, from this figure it is clear that the value of the evaporation rate is quite sensible to the relative humidity of the air.

To maintain the temperature of the air and its relative humidity and to avoid the pumping effects, it is preferable to use the sucked air sys. tem as shown in Fig. 1 than the pushed air system.

\subsection{Pressure control}

Some studies have indicated that carbon dioxide fluxes measured by dynamic chamber systems are sensitive to pressure variations. Kanemasu et al. (1974) found that the carbon dioxide flux from the soil depended strongly on

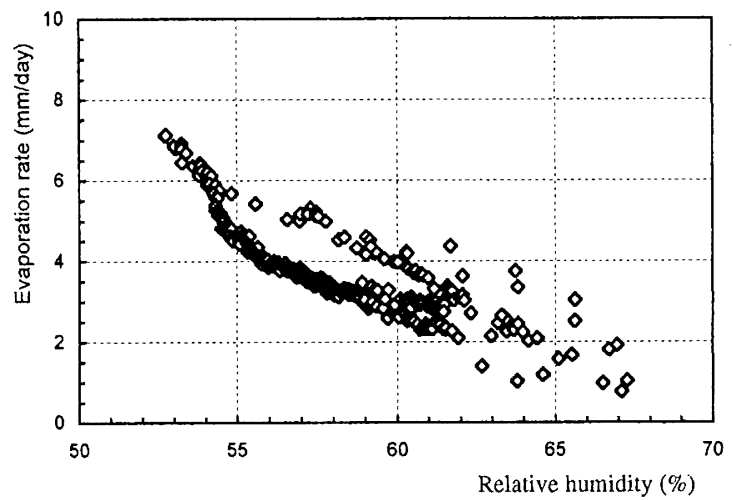

Fig. 5 Effect of the relative humidity of the air on the evaporation rate under laboratory conditions. 
whether the air was sucked or pushed through the chamber. The difference was almost an order of magnitude, with the large value obtained when air was sucked. The static pressure within the chamber becomes more or less than that of the ambient atmosphere depending on the way of forcing the air to move through the chamber. In a dynamic chamber the change of static pressure within the chamber compared with the ambient pressure, depends largely on the design of the chamber itself. In principle, the pressure change in the chamber is a function of the flow rate and the resistance against the flow.

In our chamber, the inlet and outlet of the chamber have a wide areas to allow the air to pass smoothly through them. This means that the resistance to the air flow through the chamber is minimal. The air flow rate was changed several times and the corresponding change of static pressure within the chamber compared with the ambient atmospheric pressure was measured every time. The relationship was found to be of the linear type as shown in Fig. 6. From this figure it is clear that the pressure difference is small at the low air flow rate but increasing in a linear way when the air flow rate increases. This linear relation can be expressed as follows

$$
\Delta P=-4.8223+0.01313 Q
$$

where $\Delta P$ is the change of static pressure within the chamber compared with the ambient atmosphere in $m b$ and $Q$ is the volumetric flow rate of the air through the chamber in $L / m i n$.

\section{3 Velocity distribution}

In the atmosphere the largest changes in wind, temperature and humidity usually take place in the vertical and very close to the surface. For this reason, the air near the surface may be regarded as a boundary layer, a concept set forth by Prandtl (1904) for the momentum transport in the neighborhood of a solid wall. Under the natural weather conditions, the thick- ness of the boundary layer is of the order of $10^{3}$ $m$, varying between approximately 500 and 2000 $m$ (Brutsaert, 1982). The orders of magnitude of the heights of the sublayers of the atmospheric boundary layer have been defined by Brutsaert, 1982. According to that definition, the height of the chamber of the used equipment covers both of the interfacial sublayer over its entire height and partially the dynamic sublayer.

The interfacial sublayer may be defined as the sublayer of the turbulent atmospheric boundary layer immediately adjacent to the surface but below the dynamic sublayer. In the immediate vicinity of the surface, the turbulence is strongly affected by the structure of the roughness elements, or its greatly damped by viscous effects; in most cases it is subjected to both effects. In case of smooth flow it is often referred as the viscous sublayer and its thickness in of the order of $30 v / u_{*}$, where $v$ is the kinematic viscosity and $u_{*}$ is the shear velocity. Over a rough surface it may be referred to as a roughness sublayer and its thickness is of the order of the mean height of the roughness obstacles. When the roughness obstacles consist of vegetation which is more or less porous or permeable for the air stream, the interfacial sublayer may be referred as the canopy sublayer. Within the used chamber, both of the

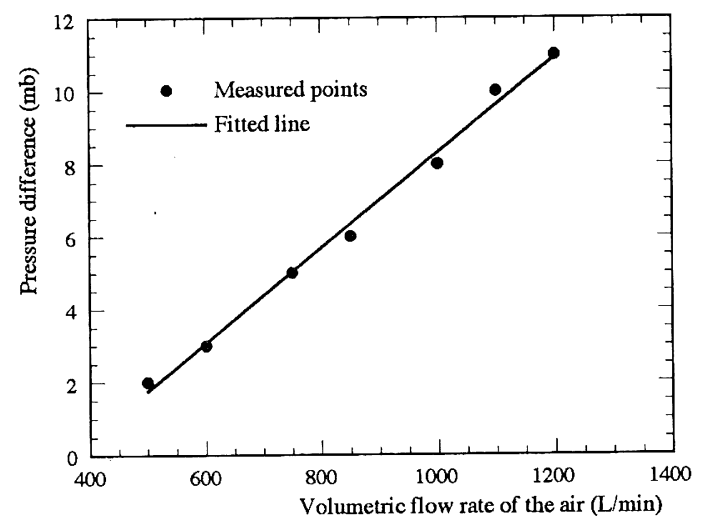

Fig. 6 Relationship between the volumetric flow rate of the air and the pressure change within the chamber compared with the ambient atmospheric pressure. 
nature of the roughness elements of the soil surface and the viscosity of the air are not altered. Therefore, the characteristics of this interfacial sublayer within the chamber are always similar to those of the same layer outside the chamber.

The dynamic sublayer consists of the fully turbulent region, which is sufficiently close to the ground surface that the effects of the Coriolis and buoyancy forces due to the density stratification are negligible; but it is far enough from the surface that both the viscosity of the air and the structure of the individual roughness elements also have no effect on the motion. Under diabatic conditions, i.e., with density stratification of the air, this layer may extend over only few meters or less, whereas under conditions of the neutral stability the dynamic sublayer occupies the entire surface sublayer. The thickness of the dynamic sublayer under the natural weather conditions varying between approximately 1 and $10 \mathrm{~m}$ (Brutsaert, 1982). It has been well verified experimentally by now, and it is therefore almost accepted by definition, that in the dynamic sublayer the profiles of the mean wind speed, mean temperature, mean specific humidity and concentration of any other admixtures, provided they are released or absorbed uniformly at the surface, are all logarithmic function of the height above the surface.

One of the main objectives of the design of this ventilated chamber is to minimize the chamber's influence on the natural conditions in the field. In nature, there is a large fluctuation in air velocity which is difficult to mimic. The average rate can, however, be adjusted to the corresponding average conditions in the field under study. With this system it is possible to adjust the ventilation rate in order to examine how sensitive evaporation from a certain surface is to a wind speed. Having a controlled ventilation makes it also possible to calculate the aerodynamic resistance within the chamber, which is of importance when, for instance, the soil surface resistance is to be calculated (Mohamed et al., 1997). This is an advantage compared to systems with fans stirring the air inside the chamber in an uncontrolled way.

Another influence of the chamber on the natural conditions is on the vertical velocity distribution of the air. To minimize this influence, the vertical velocity distribution within the chamber has to mimic that one outside the chamber. Under any condition, the height of the chamber of the used equipment $(0.80 \mathrm{~m})$ will not exceed the top boundary of the dynamic sublayer outside the chamber ( 1 to $10 \mathrm{~m}$ thickness), therefore, the air velocity within the chamber has to be a logarithmic function of the height above the surface. To get the logarithmic velocity distribution of the air within the chamber, two perforated plates are provided near its entrance and exit (see Fig. 2). A hot-wire anemometer was inserted in the chamber through the measuring openings at its ceiling to measure the velocity of the air at different heights from the surface. The vertical velocity distributions for different volumetric flow rates of the air were measured at the measuring openings No. 1 through 6 . The numerical order of the measuring openings from 1 to 6 was made according to their locations with respect to the flow direction of the air as shown in Fig. 2. It was found that the air velocity within the chamber can be roughly modeled as a logarithmic function of the height above the soil surface as

$$
U=C_{1}+C_{2} e n(Z)
$$

Where $U$ is the air velocity in $\mathrm{cm} / \mathrm{s}, Z$ is the height above the soil surface in $\mathrm{cm}$ and the parameters $C_{1}$ and $C_{2}$ depend on both of the volumetric flow rate of the air and the location of the measuring opening. Figure 7 ( $a, b$ and $c)$ illustrates the vertical velocity distribution of the air (measured points and fitted logarithmic curves) at air flow rate of $750 \mathrm{~L} / \mathrm{min}$, at the different measuring openings. From this figures it is observed that the agreement between the measured points and the fitted curves is not quite 
well. In fact, it is not so easy to regulate the air within such small spaces. Also, it is clear from this figure that the agreement is better at the measuring openings No. 1 and 2 than that at the other measuring openings. The reason may be comes from the disturbance of the flow by the stiffening plates and pipes inside the chamber at the middle part. However, the comparison between Fig. 7b and Fig. 7c shows that the effect of this disturbance is less at the measuring openings No. 5 and 6 than that at the measuring openings No. 3 and 4 . This can be explained as, the location of the measuring openings No. 5 and 6 is more close to the exit perforated plate than that of the measuring openings No. 3 and 4 . Also, it is observed that the agreement in general becomes better when the volumetric flow rate of the air increases because the two perforated plates become more active at the higher flow rates of the air. Within this portable chamber, a logarithmic wind velocity distribution can be generated instead of using a wind tunnel. Table 1 shows the values of the parameters $C_{1}$ and $C_{2}$ for four different volumetric flow rates of the air at the different measuring openings.

\section{Investigation site}

The experiment described here was conducted at Oishitai, Rokkasho-Mura, Kamikita-Gun in the south of the Shimokita Peninsula, in the north-east of Aomori Prefecture, Japan (see Fig. 8). This place presents Japan's first facility for disposing of low-level radioactive waste produced by nuclear power plants.

Prediction of the ground water flow of such places is a prerequisite for evaluating safety concerning radioactive wastes. Ground water flow can be well analyzed using some numerical techniques such as Finite Element and Finite Difference Methods, if the initial and boundary conditions of the flow and properties of the soil are

Table 1 Values of the parameters $C_{1}$ and $C_{2}$ for different volumetric flow rates of the air at the different measuring openings.

\begin{tabular}{|c|c|c|c|c|c|c|}
\hline \multirow{2}{*}{$\begin{array}{c}\text { Volumetric flow } \\
\text { rate of the air in } \\
(L / \mathrm{min})\end{array}$} & \multicolumn{3}{|c|}{$\begin{array}{c}\text { Parameter } C_{I} \text { at the specified } \\
\text { measuring openings }\end{array}$} & \multicolumn{3}{c|}{$\begin{array}{c}\text { Parameter } C_{2} \text { at the specified } \\
\text { measuring openings }\end{array}$} \\
\cline { 2 - 7 } & No. $1 \& 2$ & No. $3 \& 4$ & No. $5 \& 6$ & No. $1 \& 2$ & No. $3 \& 4$ & No. $5 \& 6$ \\
\hline 500 & 21.560 & 19.311 & 16.585 & 2.425 & 1.860 & 1.083 \\
\hline 750 & 36.448 & 31.140 & 26.946 & 3.450 & 2.320 & 2.154 \\
\hline 1000 & 40.238 & 37.945 & 36.186 & 3.731 & 3.118 & 2.849 \\
\hline 1200 & 47.563 & 46.657 & 43.139 & 4.353 & 3.670 & 3.512 \\
\hline
\end{tabular}
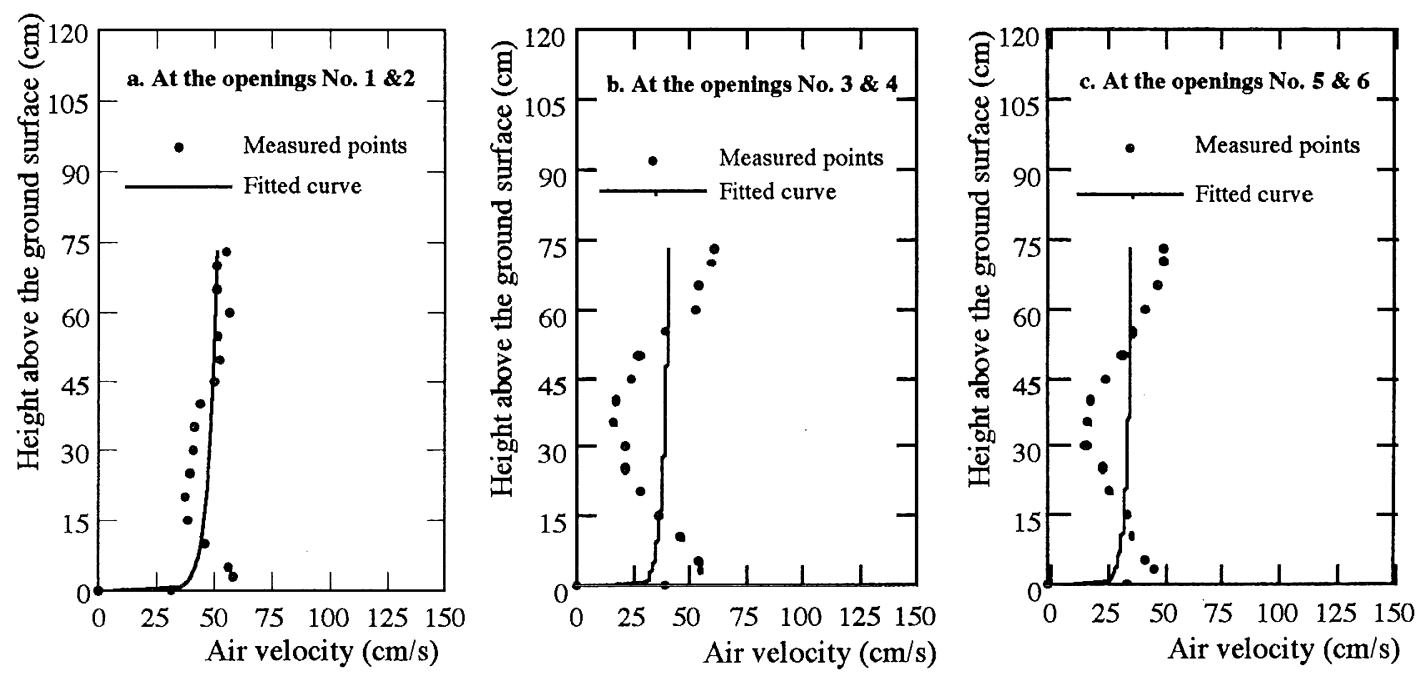

Fig. 7 Relationship between the air velocity and the height above the ground surface; (a) at the measuring openings No. $1 \& 2$, (b) at the measuring openings No. $3 \& 4$ and (c) at the measuring openings No. $5 \& 6$. 
defined. The boundary condition of the flow at the soil surface is the most difficult one to estimate and it can be defined, if the evaporation rate can be estimated.

The aim of the present study at this important site is to introduce a new equipment to measure the evaporation rate precisely and to apply a new method to estimate the main terms in the energy budget equation at the bare soil surface under the field conditions.

\section{Field experiment}

An experimental plot with dimensions of 0.50 $\mathrm{m}$ width and $1.20 \mathrm{~m}$ length was selected at Rokkasho Low-level Radioactive Waste Disposal

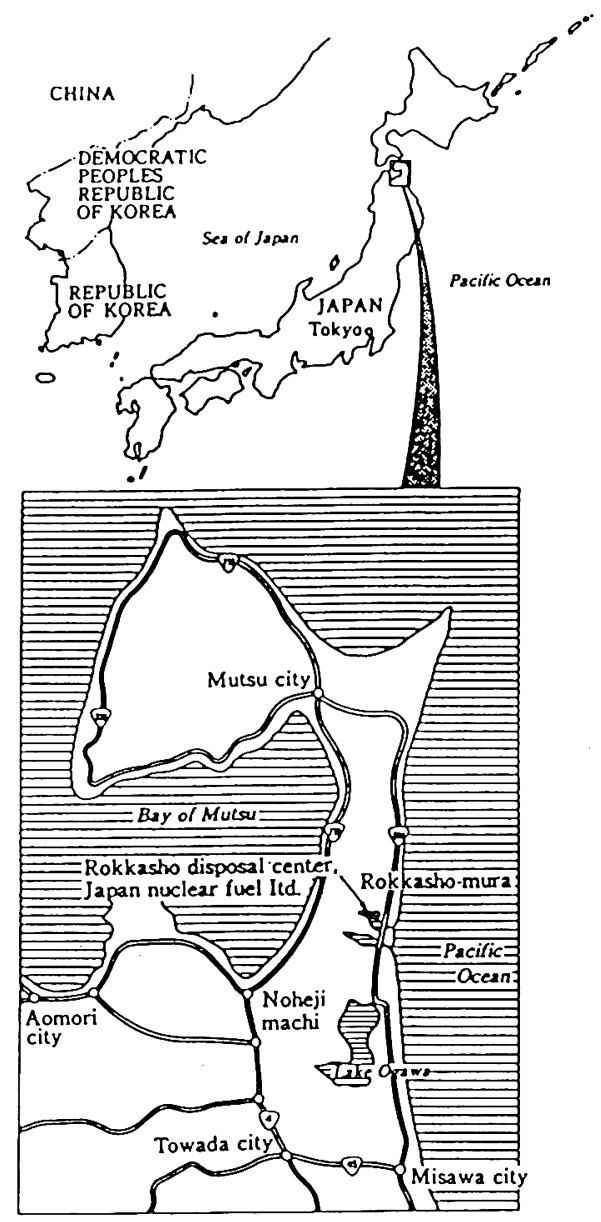

Fig. 8 Location of Rokkasho Disposal Center.
Center, Aomori Prefecture, Japan. The soil was described as a volcanic ash (Quaternary) with a porosity of $56.8 \%$ and a saturated hydraulic conductivity of $1.1 \times 10^{-5} \mathrm{~cm} / \mathrm{s}$. The thickness of this layer of soil is approximately $3.0 \mathrm{~m}$. Ten thermistors as shown in Fig. 1 were installed just beneath the ground surface and distributed over the area to measure the soil temperature at the thin top layer during the experiment. The arithmetic mean of the measured values was considered as the soil surface temperature. Two soil heat flux's plates were installed $1.0 \mathrm{~cm}$ under the soil surface and normal to the direction of the heat flow as shown in Fig. 2. The plot was saturated first, to understand better the diurnal behavior for both of the evaporation rate and the main terms in the energy balance equation at the bare soil surface under wetter conditions, such as would occur after periods of precipitation or irrigation. The experiment was begun after few days of the saturation process, to allow the settlement of an equal soil moisture distribution over the plot. The field experiment was carried out on August 23, 1997 (24 hours). During the experiment the air was sucked through the chamber by a suction pump as shown in Fig. 1. To prevent the possibility of any air leakage along the sides of the chamber, as a result of an uneven soil surface, the edge between the chamber side and the soil surface is sealed to the soil by flexible plastic 'skirts' attached in air tight manner to the sides of the chamber. The plastic 'skirts' are pressed to the soil surface by placing a string of soil on the top of them. Also, all connections between the different parts of the equipment were completely sealed to prevent any air leakage. The volumetric flow rate of the air before passing through the chamber was measured by using a hot-wire flow meter. Both of the temperature of the air and its relative humidity were measured just before and after passing through the chamber. The measured volumetric flow rate of the air, its temperature and relative humidity were sent 
directly to a computer, to calculate the evaporation rate and to store all data. The net radiation at the ground surface was measured directly with a net radiometer positioned at $0.30 \mathrm{~m}$ above the ground surface and located outside the chamber. An automatical recorder was used to register both of the measured net radiation and the soil temperature just beneath its surface as shown in Fig. 1. Two digital soil heat flux meters were used to read the soil heat flux at the locations of the two buried plates. Soil heat flux measurements were carried out through a part time of the field experiment (from 9:20 A.M. to 3:20 P.M.). The radings of the soil heat flux were observed every 20 minutes.

\section{Observed data}

Twenty four hours field experiment was carried out at Oishitai, Rokkasho-Mura, Kamikita-Gun in the south of the Shimokita Peninsula, in the north-east of Aomori Prefecture, Japan, on a bare soil surface on August 23, 1997. Ten minutes average values of the volumetric flow rate of the air, net radiation flux, temperature of the sucked air before and after passing through the chamber, relative humidity of this air before and after passing through the chamber and the soil temperature just beneath its surface were used for calculations and illustrations. The volumetric flow rate of the air was almost constant during the field experiment with an average value of 750 $\mathrm{L} / \mathrm{min}$. Some of the observed data were plotted as shown in Figs. 9 through 12. The diurnal cycle of the measured net radiation outside the chamber at $0.30 \mathrm{~m}$ above the ground surface is presented in Fig. 9 and it shows that the day of the field experiment was almost clear. Simultaneous measurements of the net radiation were done inside as well as outside the chamber of the used equipment shown in Fig. 1, to estimate how the net radiation was affected by the chamber. These field measurements were carried out on Feb. 4,
1998, in the Campus of Saitama University, Japan. It was found that the net radiation within this chamber is reduced by about $4.46 \%$. Itritz et al. (1997) found that the net radiation within another chamber, that was used in their experiments, is reduced by $8 \%$. The reduced percentage of the net radiation by such chambers depends on the characteristics of the chamber itself such as its dimensions, shape and material. To check the effect of the net radiation on the air temperature, air relative humidity and the soil temperature just beneath its surface, their observations at Rokkasho Disposal Center on August 23, 1997, were plotted as shown in Figs. 10 through 12 respec-

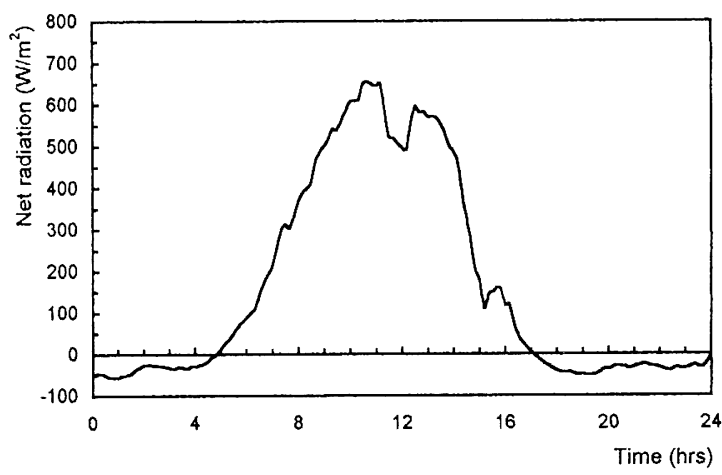

Fig. 9 The daily cycle of the net radiation at the bare soil surface outside the chamber on August 23, 1997, at Rokkasho Disposal center.

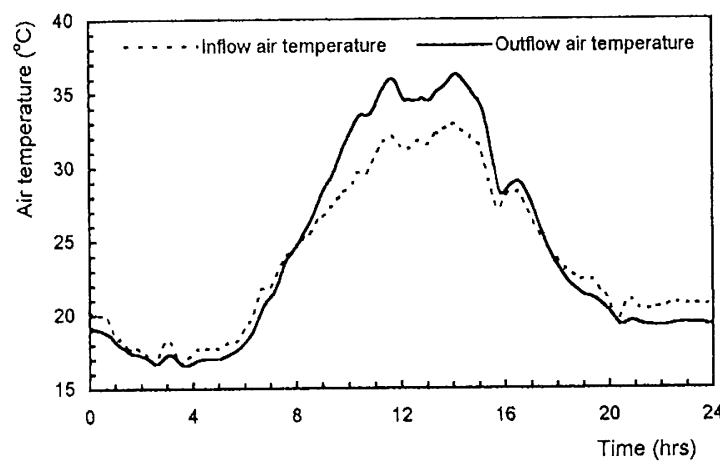

Fig. 10 Diurnal variation of the temperature of the inflow and outflow air during the field experiment, at Rokkasho Disposal Center on August 23, 1997. 
tively. It is observed that, each of these parameters is quite sensible to the value of the net radiation moment by moment.

\section{Description and analysis}

\subsection{Energy budget equation}

For practical purposes, the energy budget equation in a general form is

$$
R_{n}-L_{e} E-H+L_{p} F_{p}-G+A_{h}=\frac{\partial W}{\partial t}
$$

where the energy fluxes toward the layer are taken as positive and those away from it as negative as illustrated in Fig. 13 (the general form).

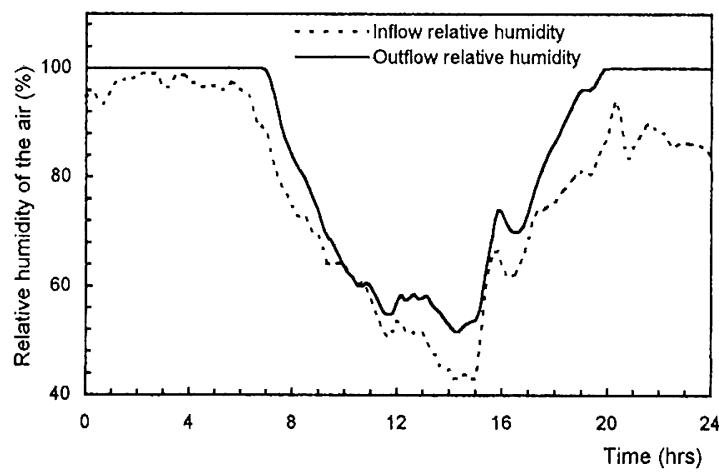

Fig. 11 Measured relative humidity of the inflow and outflow air during the field experiment, at Rokkasho Disposal Center on August 23, 1997.

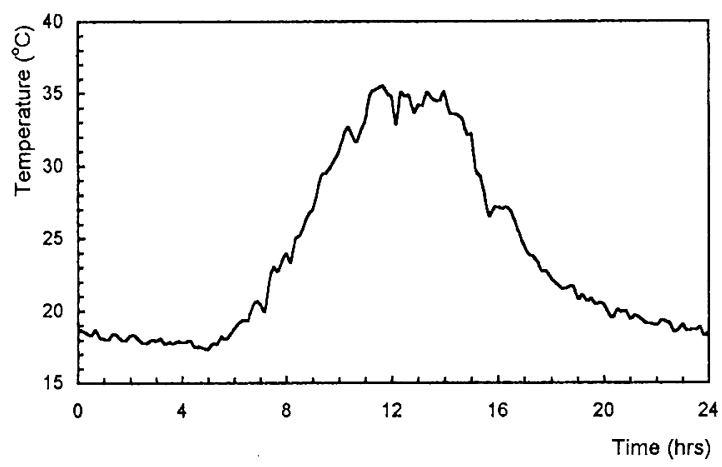

Fig. 12 Transient change of the soil temperature just beneath its surface during the field experiment, at Rokkasho Disposal Center on August 23, 1997.
$R_{n}$ is the net radiation flux density at the upper surface of the layer, $L_{e}$ is the latent heat of vaporization, $E$ is the evaporation rate from the upper surface of the layer, $H$ is the sensible heat flux into the atmosphere, $L_{p}$ is the thermal conversion factor for fixation of carbon dioxide, $F_{p}$ is the specific flux of carbon dioxide, $G$ is the soil heat flux leaving the layer at its lower boundary, $A_{h}$ is the energy advection into the layer expressed as specific flux and $\frac{\partial W}{\partial t}$ is the rate time of the energy storage per unit area in the layer. In the case of an ice or snow layer the last term in Eq. (3) may include the energy consumed by fusion and $L_{e}$ may have to be replaced by $L_{s}$, the latent heat of sublimation.

The exact nature of several of the terms of Eq. (3) depends on the type of the layer or substrate for which the energy balance is written. For a bare soil surface both of the photosynthesis term and the energy consumed by fusion of ice can be omitted. For a thin layer of soil has a unit area, the lateral advection of the heat through the vertical wall of this thin layer at its boundary is proportional to the area of the wall itself, therefore, it will be small and can be neglected. Also, for a thin layer of soil has a unit area and a small thickness (small volume), the total capacity of this layer for energy storage will be small. Therefore, the change of the stored energy in that layer during a certain period under the normal conditions will be small also and can be omitted. Now, by leaving out the effects of the photosynthesis, ice melt, lateral advection and unsteadiness as shown in Fig. 13 (the simple form), a much simpler form of Eq. (3) as in Brutsaert, 1982 can be given as

$$
R_{n}-L_{p} E-H-G=0
$$

where all terms have been previously defined. From the observed data each of the energy budget terms presented in Eq. (4) was calculated or directly measured. 


\subsection{Net radiation flux}

The net radiation is the difference between incoming and outgoing radiant fluxes integrated over all wave-lengths. A common characteristic of most energy budget methods is that, they require the determination of the net radiation. The net radiation can be broken down into several components. Whenever possible, the net radiation should be measured, and at present, fairly reliable instruments are available for this purpose. Therefore, in this work, the net radiation flux was measured directly by a net radiometer positioned at $0.30 \mathrm{~m}$ above the ground surface and located outside the chamber (see Fig. 1). As it was explained before that the net radiation within this chamber is reduced by about $4.46 \%$. Therefore, we considered only $95.54 \%$ of the measured net radiation outside the chamber in the calculation of the energy balance within the chamber.

\subsection{Latent heat flux}

The latent heat flux can be calculated from the multiplication of the evaporation rate by the

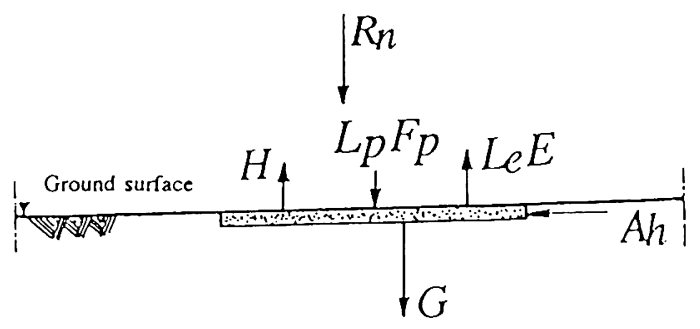

The general form

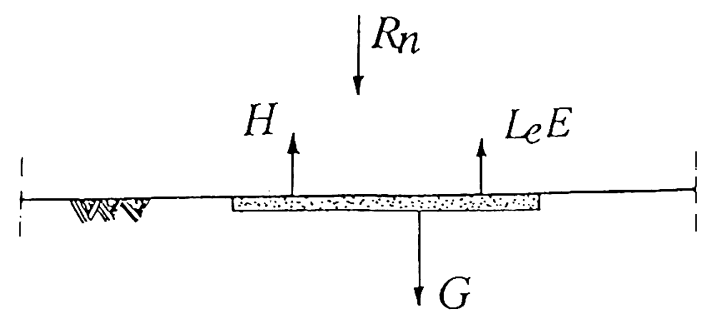

The simple form

Fig. 13 Energy balance components at the ground surface. latent heat of vaporization. The absolute humidity of the sucked air before and after passing through the chamber is necessary for the calculation of the evaporation rate. The absolute humidity of the air can be calculated from its temperature and relative humidity (Brutsaert, 1982) as follows

$$
\begin{aligned}
e_{a}^{*}= & 1013.25 \exp \left(13.3185 t_{R a}-1.9760 t_{R a}^{2}\right. \\
& \left.-0.6445 t_{R a}^{3}-0.1229 t_{R a}^{4}\right) \\
t_{R a}= & 1-\frac{373.15}{T_{a}} \\
\mathrm{e}_{a}= & \frac{\mathrm{e}_{a}^{*} \mathrm{~h}}{100} \\
\beta= & 10^{5} \times \frac{0.622 e_{a}}{R_{d} T_{a}}
\end{aligned}
$$

where $e_{a}^{*}$ is the saturated vapor pressure at the air temperature in $m b, T_{a}$ is the temperature of the air in $K, e_{a}$ is the vapor pressure of the air in $m b, h$ is the relative humidity of the air (\%), $\beta$ is the absolute humidity of the air in $\mathrm{g} / \mathrm{m}^{3}, R_{d}$ is the gas constant for dry air $\left(287.04 \mathrm{~J} \mathrm{~kg}^{-1} \mathrm{~K}^{-1}\right)$ and the constant 0.622 is the ratio of the molecular weights of water and dry air. From the volumetric flow rate of the air and its absolute humidity just after and before passing through the chamber, the evaporation rate can be simply calculated from the following basic equation as

$$
E=-1.44 \times 10^{3} \times \frac{Q\left(\beta_{\text {out }}-\beta_{\text {in }}\right)}{\rho_{w} A}
$$

where $E$ is the evaporation rate in $m m / d a y, Q$ is the volumetric flow rate of the air in $L / \mathrm{min}, \beta_{\text {out }}$ and $\beta_{\text {in }}$ are the absolute humidity in $\mathrm{g} / \mathrm{m}^{3}$ of the air after and before passing through the chamber respectively, $\rho_{w}$ is the density of the water in $g / \mathrm{m}^{3}$ and $A$ is the area covered with the chamber in $m^{2}$. Figure 14 shows the transient change of the evaporation rate through the field experiment, at Rokkasho Disposal Center on August 23, 1997.

The latent heat of vaporization depends mainly on the temperature of the evaporating surface (Brutsaert, 1982) and it can be obtained from 


$$
L_{e}=\frac{R_{d} T_{s}^{2}}{0.622 e_{s}^{*}} \frac{d e_{s}^{*}}{d T_{s}}
$$

where $L_{e}$ is the latent heat of vaporization in $J$ $k g^{-1}, T_{s}$ is the soil surface temperature as the evaporating surface in $K, e_{s}^{*}$ is the saturated vapor pressure at the soil surface temperature in $m b, \frac{d e_{s}^{*}}{d T_{s}}$ is the rate of change of the saturated vapor pressure with respect to the soil surface temperature in $m b K^{-1}$ and all other variables have been previously defined.

The saturated vapor pressure at the soil surface temperature $\left(e_{s}^{*}\right)$ can be calculated from Eqs. (5) and (6) by using the soil surface temperature $\left(T_{s}\right)$ instead of the air temperature $\left(T_{\mathrm{a}}\right)$. The variation of the saturated vapor pressure with the soil temperature $\left(\frac{d e_{s}^{*}}{d T_{s}}\right)$ in $m b K^{-1}$ can be calculated from the following two equations

$$
\begin{aligned}
\frac{d e_{s}^{*}}{d T_{s}}= & \frac{373.15 e_{s}^{*}}{T_{s}^{2}}\left(13.3185-3.9520 t_{R s}\right. \\
& \left.-1.9335 t_{R s}^{2}-0.5196 t_{R s}^{3}\right) \\
t_{R s}=1 & -\frac{373.15}{T_{s}}
\end{aligned}
$$

where $T_{s}$ is the soil surface temperature in $K$ and all other variables has been previously defined.

\section{4 Sensible heat flux}

The sensible heat flux from the soil $(H)$ can be calculated from the following two components as

$$
H=H_{a}+H_{w}
$$

where $H_{a}$ is the component of the sensible heat flux taken by the moving air inside the chamber and $H_{w}$ is the other component of the sensible heat flux that comes in or goes out through the chamber's wall to the ambient atmosphere due to the temperature difference between inside and outside the chamber.

The sensible heat flux taken by the moving

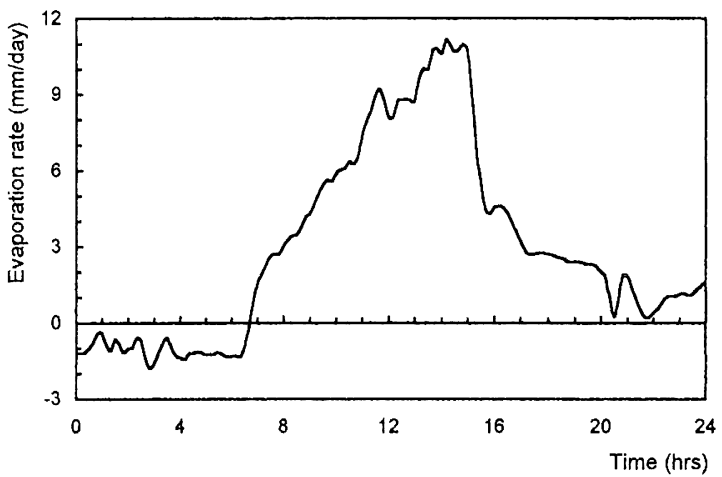

Fig. 14 Transient change of the evaporation rate during the field experiment on August 23, 1997, at Rokkasho Disposal Center.

air inside the chamber $\left(H_{\mathrm{a}}\right)$ in $W / \mathrm{m}^{2}$ can be expressed as follows

$$
H_{\mathrm{a}}=\frac{-1}{60 \times 10^{6}} \times \frac{Q \rho_{a} C_{p}\left(T_{\text {a(iin) }}-T_{\alpha(\text { ant }}\right)}{A}
$$

where $Q$ is the volumetric flow rate of the air in $L / m i n, \rho_{a}$ is the density of the moist air in $\mathrm{g} / \mathrm{m}^{3}$, $C_{P}$ is the specific heat of the moist air at constant pressure in $J \mathrm{~kg}^{-1} K^{-1}, T_{\text {a(in) }}$ and $T_{\text {a(out) }}$ are the temperature of the air $(K)$ before and after passing through the chamber respectively and $A$ is the area covered with the chamber in $m^{2}$. The specific heat of the moist air at constant pressure $\left(C_{P}\right)$ is the weighted sum of the specific heats of the dry air and the vapor components (Brutsaert, 1982) and it is given by

$$
\begin{aligned}
& C_{P}=C_{P_{d}}(1+0.84 q) \\
& q=\frac{\beta}{\rho_{a}}
\end{aligned}
$$

where $C_{P d}$ is the specific heat of dry air $\left(1005 \mathrm{~J} \mathrm{~kg}^{-1}\right.$ $\left.K^{-1}\right), q$ is the specific humidity of the air (ratio), $\beta$ is the absolute humidity of the air in $\mathrm{g} / \mathrm{m}^{3}$ and $\rho_{a}$ is the density of the moist air in $\mathrm{g} / \mathrm{m}^{3}$.

The second component of the sensible heat flux is that heat comes in or goes out through the chamber's wall to the ambient atmosphere due to the temperature difference between inside and 
outside the chamber $\left(H_{\mathrm{w}}\right)$. The value of this heat in $W / m^{2}$ can be formulated by Fourier's law as

$$
H_{w}=-\lambda \frac{\Delta T}{\Delta n} \times \frac{A_{1}}{A}
$$

in which $\lambda$ is the thermal conductivity in $W m^{-1}$ $K^{1}, \Delta T$ is the temperature difference between inside and outside the chamber in $K, \Delta n$ is the chamber's wall thickness in $m, A_{1}$ is the total area of the chamber's wall including its ceiling in $\mathrm{m}^{2}$ and $A$ is the area covered with the chamber in $m^{2}$. The termal conductivity $(\lambda)$ of the acryl material of the chamber was taken as $0.17 \mathrm{~W} \mathrm{~m}^{-1} \mathrm{~K}^{-1}$ (Rika Nenpyo, 1997). The temperature difference between inside and outside the chamber was taken as a third of the temperature difference between the inflow and outflow air, because the temperature of the air outside the chamber is equal to the temperature of the inflow air. The sensible heat flux into the atmosphere was calculated by using Eq. (13) after calculating its two components.

\subsection{Soil heat flux}

The soil heat flux evaluates the amount of the energy flux leaving or entering the surface layer of the soil at its lower boundary. The direction of this energy term depends on the fact that, when different parts of a body are at different temperatures, heat flows from the hotter parts to the cooler. The soil heat flux can be solved numerically as a function of the thermal conductivity of the soil and the vertical temperature gradient (Camillo et al., 1983). This approach may be difficult to apply over heterogeneous areas. In general, the energy budget method allows the determination of one of the terms of the general Eq. (3), or any simple form of it, when all the remaining terms can be determined by some independent methods. Therefore, the soil heat flux was estimated from Eq. (4) as the remaining unknown term, while all other terms except it have been previously measured or calculated.

\subsection{Diurnal variation of the energy balance components}

Figure 15 shows the ten-minutes average values of the net radiation, latent heat, sensible heat and soil heat fluxes measured or calculated by the previous articles for the whole day of the field experiment at Rokkasho Disposal Center, on August 23, 1997. As shown in this figure, all of these terms depend mainly on the net radiation. The reason is that, the net radiation strongly affects the air relative humidity, the air temperature and the soil temperature at the top layer as mentioned before. However, the net radiation was varied widely from hour to another during the day time. These weather variations present a check of the operational effectiveness of the used equipment.

The integration of the energy budget terms over the 24 hours of the field experiment resulted in, the latent heat flux constituted $54.36 \%$, the sensible heat flux $22.98 \%$ and the soil heat flux $22.66 \%$ of the received net radiation. The integrated values showed a large partitioning for the latent heat flux more than that indicated by the maximum rate. So, in conclusion, the latent heat flux uses a significant proportion of the available energy seen over the full diurnal cycle, especially in case of the wetted soil surface. This also

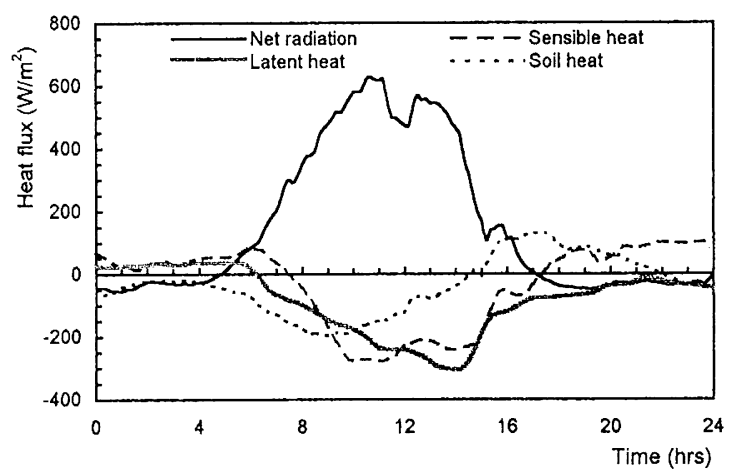

Fig. 15 The daily cycle of the energy balance components for a bare soil surface on August 23, 1997, at Rokkasho Disposal Center. 
implies that accurate modeling of evaporation is important.

\section{Accuracy check of the new method}

The soil heat flux was calculated from Eq. (4) as the remaining unknown term, so it includes not only its calculation error but also the error of the other three terms of the equation. Therefore, the soil heat flux was chosen to evaluate the accuracy of this new method to separate the energy balance components at the bare soil surface. The soil heat flux component was measured directly through a part time of the field experiment carried out at Rokkasho Disposal Center, on August 23, 1997 and a comparison between the measured values and those have been calculated by this method was done. Figure 16 shows the transient change of both of the calculated and measured values of the soil heat flux through a part time of the field experiment. In spit of this difference appears to belong to the soil heat flux only but in fact it is the total error in the estimation of the energy balance components as a whole plus the measuring error of the soil heat flux. In the comparison between the measured and the calculated values of the soil heat flux, it is not so valid to relate the whole difference to the calculated value, by considering the measured one is absolutely correct. Problems in the measurement of the soil heat flux may arise from poor contact between the plate and the soil and from possible interference of the plate with the soil water movement. Also, the thermal properties of the plate material are likely to be different from those of the soil, which vary with moisture content. If this difference is large or if the plate is placed too close to the surface, the soil heat pattern may be distorted considerably. It is extremely difficult to estimate how much these factors affect the measured values of the soil heat flux.

To check the amount of this error relative to the original components containing it, the total percentage of error was calculated by dividing the difference between the measured and the calculated values of the soil heat flux by the sum of the absolute values of the energy balance components. The transient change of the total percentage of error through a part time of the field experiment was plotted as shown in Fig. 17. From this figure it is obvious that the percentage of error is not so big and it can be highly accepted under field conditions.

\section{Conclusions}

With this portable equipment and simple method a satisfactory estimation of both of the evaporation rate and the main terms in the energy budget equation at the bare soil surface can be continuously made under the field conditions. The obtained results are;

(1) A new device for continuous computing and recording of both the evaporation rate and the energy balance components at the bare soil surface in the field is described with some of its principle advantages and characteristics.

(2) A new method for estimating the heat balance components at the bare soil surface was proposed. This method needs only simple data and it wears an aspect of certainty.

(3) The results of a fild trial over a bare soil surface demonstrate the new method reliability and the operational effectiveness of the measuring equipment for experimental periods of many days.

(4) The design of a new system of a dynamic chamber with a minimal effect on the natural conditions has been described. With this system it is also possible to adjust the ventilation rate in order to examine how sensitive evaporation from a certain surface is to a wind speed.

(5) The system is mobile and the chamber can be easily moved to a new plot within a short 


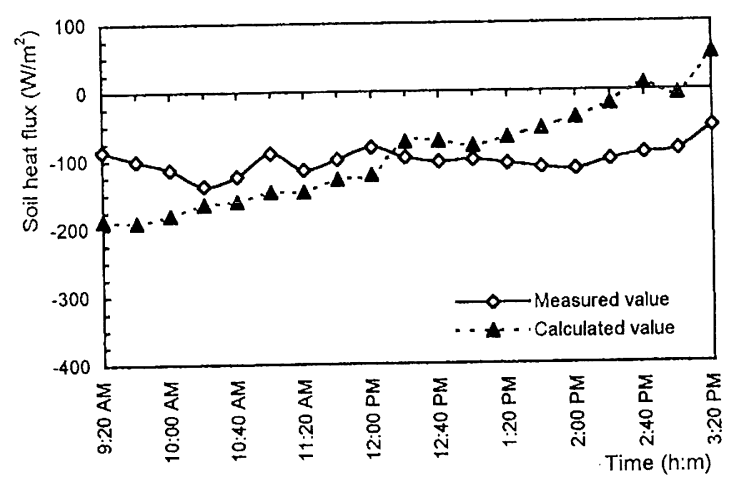

Fig. 16 Comparison between the measured and the calculated values of the soil heat flux through a part time of the field experiment, at Rokkasho Disposal Center.

time.

(6) For such kind of ventilated chamber, it was found that the sucked air system is better than the pushed one to minimize the chamber's influence on the natural conditions in the field.

(7) The change of static pressure within the chamber compared with the ambient atmospheric pressure was modeled quite well as a linear function of the volumetric flow rate of the air.

(8) A logarithmic wind profile of the flowing air inside the chamber was established for different values of the volumetric flow rate of the air.

(9) The latent heat flux uses a significant proportion of the available energy seen over the full diurnal cycle, this implies that the accurate modeling of the evaporation is important.

(10) The results of the accuracy check of the new method is a strong indicator that this method is a suitable and accurate method for separating the heat balance components at the bare soil surface.

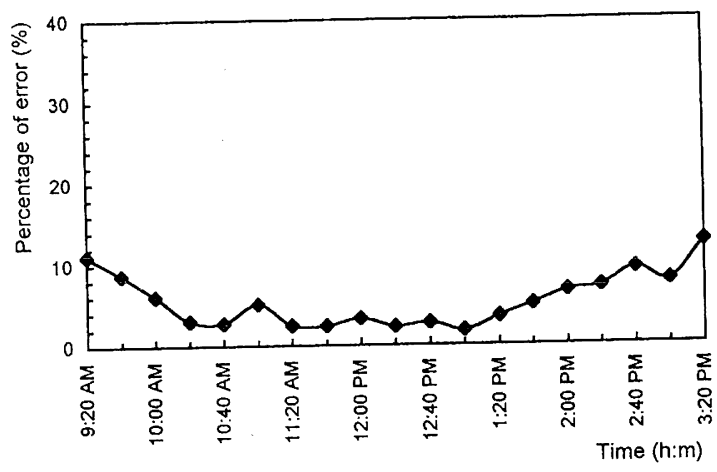

Fig. 17 Transient change of the total percentage of error through a part time of the field experiment, at Rokkasho Disposal Center.

\section{Acknowledgment}

The authors would like to express their great gratitude and thanks to reviewers of editing committee, J. Groundwater Hydrology, for their valuable time spent on reviewing the paper, for their corrections of inconsistencies, professional suggestions and comments. Also, the authors are indebted to Professor Momii for his comments and helpful reviews of this manuscript.

\section{References}

Baker J.M. and E.J.A. Spaans (1994): Measuring water exchange between soil and atmosphere with TDR-mic rolysimetery. Soil Sci., 158, 22-29.

Brutsaert H. (1982): Evaporation into the atmosphere. Kluwer Adademic Publisher.

Camillo P.J., R.J. Gurney and T.J. Schmugge (1983): A soil and atmospheric boundary layer medel for evapotranspiration and soil moisture studies. Water Resour. Res., 19, 371-380.

Denmead O.T. (1984): Plant physiological methods for studying evapotranspiration: problems of telling the forest from the trees. Agric. Water Manag., 8, 167-189.

De Vries D.A. (1958): Simultaneous transfer of heat and moisture in porous media. Trans. Am. Geophys. 
Un., 39, 909-916.

Iritz Z., A. Lindroth and A. Gärdenäs (1997): Open ventilated chamber system for measurements of $\mathrm{H}_{2} \mathrm{O}$ and $\mathrm{CO}_{2}$ fluxes from the soil surface. Soil Technology, 10, 169-184.

Kanemasu E.T., W.L. Powers and J.W. Sij (1974): Field chamber measurements of $\mathrm{CO}_{2}$ flux from soil surface. Soil Sci., 118, 233-237.

Kurokawa U., K. Watanabe, A.K. Abdel-Lah and T. Yamamoto (1995): The accuracy of the new equipment for measuring evaporation and characteristics of the evapotranspiration from plants under different conditions. J. Japan Soc. Eng. Geol., 34(4), $27-33$

Leuning R.L. and I.J. Foster (1990): Estimation of transpiration by single trees: comparison of a ventilated chamber, leaf energy budgets and a combination equation. Agric. For. Meteorol., 51. 63-86.

Mohamed A.A., K. Watanabe and U. Kurokawa (1997): Simple method for determining the bare soil resistence to evaporation. Journal of Groundwater Hydrology, $39(2)$, 97-113.

Nenpyo R. (1997): Chronological scientific tables. Maruzen Co., Ltd.

Perrier A., B. Itier, J.M. Bertolini and N. Katerji (1976): A new device for continuos recording of the energy balance of natural surfaces. Agric. Meteorol. $16,71-84$.

Philip J.R. (1957): Evaporation, and moisture and heat fields in the soil. J. Meteorol., 14, 354-366.

Plauborg F. (1995): Evaporation from bare soil in a temperate humid climate-measuring using micro-lysimeters and time domain reflectrometry. Agric. For. Meteor., 76, 1-17.

Prandtl L. (1904): Ueber flüssigkeitsbewegung bei sehr kleiner reibung. Verhandl. III, Internat. Math.-Kong., Heidelberg, Teubner, Leipzig, 484-491.

Pruitt W.O., D.L. Morgan and F.J. Lourence (1968): Energy, momentum and mass transfers above vegetative surfaces. Tech. Rept. ECOM-0447 (E)-F, Dept. Water Sci. Eng., Univ. Calif., Davis, 49 pp.

Raupach M.R. (1978): Infrared fluctuation hygrometry in the atmospheric surface layer. Quart. J. Roy. Meteorol. Soc. 104, 309-322.

Watanabe K. and Y. Tsutsui (1994): A new equipment used for measuring evaporation in a field. Proc. 7th Congr., IAEG, 309-313.

Yasuda N. (1975): The heat balance at the sea surface observed in the East China Sea, Sci. Rep. Tohoku Univ. (Sendai, Japan), Ser. 5, Geophys. 22, 87-105.

（受付：1997年10月 7 日、受理：1998年 4 月 1 日） 